\title{
"AS PESSOAS FICAM RECLAMANDO DO JEITO QUE A CRIANÇA É": AS RELAÇÕES DE GÊNERO NAS AULAS DE EDUCAÇÃO FÍSICA NA EDUCAÇÃO INFANTIL EM AMARGOSA/BA
}

\author{
Daniela Souza Nunes ${ }^{1}$ \\ Priscila Gomes Dornelles ${ }^{2}$
}

\begin{abstract}
Resumo: Este texto problematiza as relações de gênero em aulas de Educação Física na Educação Infantil no interior baiano, buscando compreender como estas relações organizam a referida disciplina e se constituem neste nível de ensino. Para isso, dialogamos com o conceito de gênero a partir dos Estudos Feministas, priorizando as produções de segunda onda, buscando ainda relacionar educação, cultura e gênero. A pesquisa que gerou este artigo constituiu-se em uma abordagem qualitativa realizada na cidade de Amargosa/BA. Realizamos entrevistas com 10 (dez) participantes, a saber, professores/as da Educação Infantil e estagiários/as do nível de ensino supracitado, do curso de Licenciatura em Educação Física da Universidade Federal do Recôncavo da Bahia. Compreendemos assim que as aulas de Educação Física na Educação Infantil são organizadas com base na separação de meninos e meninas.
\end{abstract}

Palavras-chave: Educação física escolar; Relações de gênero

\section{"PEOPLE KEEP COMPLAINING ON THE WAY A CHILD IS": GENDER RELATIONS IN PHYSICAL EDUCATION CLASSES ON CHILDHOOD EDUCATION IN AMARGOSA, BAHIA}

\begin{abstract}
This paper raises questions on gender relations in physical education classes in Childhood Education in the city of Amargosa, state of Bahia. We sought to understand how these relations set Physical Education classes as presented in this level of early childhood teaching. We carried out the concept of gender from the perspective of Second-Wave Feminism Studies, and still looking for connections with education and culture. From a qualitative standpoint we also performed interviews with Child education teachers and trainees who teach classes for children at Stage I undergraduate Physical Education course of Federal University of Reconcavo Baiano. Finally, we were able to analyze how gender transverses P.E. classes in childhood education by organizing these classes based on splitting boys and girls, and gender naturalization as reference for students body.
\end{abstract}

Keyword: School Physical Education; gender relations

\footnotetext{
${ }^{1}$ Graduada em Licenciatura em Educação Física pela Universidade Federal do Recôncavo Da Bahia (2017). Tem experiência na área de Educação, com ênfase em Educação Física.

${ }^{2}$ Doutorado em Educação pela Universidade Federal do Rio Grande do Sul, Brasil (2013) Professor Assistente da Universidade Federal do Recôncavo da Bahia, Brasil.
} 


\section{INTRODUÇÃO}

Neste artigo abordamos sobre as relações de gênero no ambiente escolar e como essas relações circulam e se organizam a ponto de determinar quais as práticas corporais dos/as alunos/as no decorrer das aulas de Educação Física. Assim, apresentamos uma reflexão sobre a escola como uma instituição cultural, discutindo a partir daí o papel da mesma no processo educacional, sendo que a separação entre meninos e meninas é algo recorrente nas aulas de Educação Física na Educação Infantil. Discutimos também sobre o corpo e a cultura, refletindo a respeito da interferência da mesma nos corpos infantis, aproximando-os/as à padrões exigidos pela cultura regente através dos modos de agir, pensar e se comportar.

Buscamos também abordar gênero diferentemente de sexo, pois, o gênero engloba relações de poder, cultura e educação e não somente o biológico, mais sim muitos conhecimentos culturais que nos foram acrescentados pela cultura na qual estamos inseridos.

Contribuindo com este debate, Stuart Hall (1997, p. 19) afirma que "cada movimento que fizemos é normativamente regulado no sentido de que, do início ao fím, foi guiado por um conjunto de normas e conhecimentos culturais". Assim podemos associar gênero e o conceito de cultura para problematizarmos e compreendermos como os movimentos, os gestos, os gostos, os desejos, as práticas representadas pelas crianças na Educação Infantil são influenciadas e moldadas pela/na normatização cultural.

Destarte, para desenvolver essas discussões, apresentamos os procedimentos metodológicos tomados para a realização da pesquisa, depois discutimos as relações de gênero na Educação Infantil e logo depois, trazemos algumas discussões sobre a Educação Física escolar nesse nível de ensino. Finalizando assim, com as considerações finais.

\section{PROCEDIMENTOS METODOLÓGICOS}

A pesquisa foco deste artigo foi realizada com professores/as do ensino básico que lecionam em um distrito ${ }^{3}$ localizado na zona rural do município de Amargosa/BA ${ }^{4}$

\footnotetext{
${ }^{3}$ Este distrito tem aproximadamente mais de 4 mil habitantes, está localizado no Território de Identidade do Vale do Jiquiriçá, na Messoregião Centro sul baiano e Microrregião Homogênea de Jequié. Situa-se entre o limite de Amargosa e São Miguel das Matas. (Blog de Corta-Mão).
} 
e com estagiários/as do curso de Licenciatura em Educação Física da Universidade Federal do Recôncavo da Bahia que já atuaram na Educação Infantil durante o componente Estágio em Educação Física I - destinado à experiência com a docência na Educação Infantil e nos Anos Iniciais do Ensino Fundamental, segundo o Projeto Político-Pedagógico do Curso.

O uso da entrevista se constituiu como estratégia fundamental para esta pesquisa, pois este instrumento permite ouvir os/as sujeitos do campo da pesquisa de modo a compreendermos suas posições em relação a determinadas questões sociais e ao seu cotidiano de trabalho. Deste modo, utilizamos a entrevista porque consideramos que este instrumento permitiria que os/as sujeitos com experiência na educação física na educação infantil pudessem narrar as relações de gênero no cotidiano das suas aulas.

Ainda sobre as entrevistas, Antônio Gil (2004) nos diz que,

Pode-se definir entrevista como a técnica em que o investigador se apresenta frente ao investigado e lhe formulam perguntas, com o objetivo de obtenção dos dados que interessam à investigação. A entrevista é, portanto, uma forma de interação social. Mais especificamente, é uma forma de diálogo assimétrico, em que uma das partes busca coletar dados e a outra se apresenta como fonte de informação. (p. 109).

Assim, operamos com entrevistas semiestruturadas, com um roteiro de entrevistas contendo dezessete questões. As entrevistas foram realizadas individualmente no segundo semestre de 2016 e foram negociadas da seguinte forma: entramos em contato com os/as professores/as e estagiários/as que lecionaram na Educação Infantil e explicamos como iria acontecer a entrevista, daí marcamos de nos encontrarmos em algum lugar tranquilo onde fosse possível gravar a entrevista, algumas ocorreram em uma sala na UFRB, outras nas suas próprias residências, nesse encontro explicamos sobre o que a pesquisa abordava e apresentamos o termo de consentimento livre e esclarecido que foi e lido e sanado as dúvidas.

Após a coleta de dados, realizamos a etapa de transcrição das entrevistas. Para análise e produção das categorias analíticas, produzimos uma tabela dividindo as categorias mais relevantes correlacionando-as com as posições e argumentações de autores/as sobre as relações de gênero na escola e na Educação Física escolar.

${ }^{4}$ Está localizada na mesorregião do Centro-Sul Baiano, no Vale do Jiquiriçá com População estimada de 34.351 (Censo 2010). 
A presente pesquisa se dividiu em dois grupos compostos por 5 professores/as cada grupo, totalizando $10(\mathrm{dez})$ professores/as entrevistados/as. A subdivisão foi da seguinte forma, o primeiro grupo foi com 5 professores/as que lecionam na zona rural de Amargosa que atuam ou atuaram na Educação Infantil sendo graduados ou não em Educação Física e o segundo grupo foi de 5 professores estagiários de educação física que já atuaram na Educação Infantil durante o primeiro estágio. Foram utilizados nomes fictícios para os/as professores/as participantes da pesquisa, sendo eles/as: Malú, Ana, Beatriz, Carmem, Igor, Lúcia, Tatiana, Gabriel, Eva e Vitória. Sendo que Malú, Ana, Lúcia, Carmem e Eva são professoras da Educação Infantil e Igor, Gabriel, Tatiana, Beatriz e Vitória são professores/as estagiários/as de Educação Física na Educação Infantil.

Dessa forma, tivemos a colaboração de professores/as com formação em Pedagogia, Letras, estagiários do $7^{\circ}$ semestre de Educação Física e uma professora aposentada, todos/as eles/as ensinam ou já ensinaram na Educação Infantil.

Sendo assim, essas entrevistas colaboraram para nos levar a refletir sobre as representações de gênero existentes na escola, nos levando a pensar sobre os tipos de educação que organizam os corpos na instituição escolar.

\section{CORPO, GÊNERO E EDUCAÇÃO}

Segundo Joan Scott (1995. p. 72), "a palavra gênero é assumida pelo movimento feminista e indicava uma rejeição ao determinismo biológico implícito no uso de termos como 'sexo' ou 'diferença sexual'”. Sendo assim, o conceito de gênero passa por transformações e ressignificações importantes no decorrer do tempo. No Brasil, segundo Guacira Louro (1997, p. 23) será já no final dos anos 80 que feministas passarão a utilizar o termo "gênero".

Assim, "para que se compreenda o lugar e as relações de homens e mulheres numa sociedade importa observar não exatamente seus sexos, mas sim tudo o que socialmente se construiu sobre os sexos" (ibidem, p. 21). Dessa forma, assumimos uma posição na qual gênero não é definido por um fator biológico, como se a matriz do gênero e sua produção se desse a partir das diferenças dos sexos. Diferente disto, acionamos o gênero como uma produção que se constitui através das relações sociais, levando em consideração tudo o que posicionado culturalmente para os sexos. Para Scott (1995, p. 7), “o uso de 'gênero' enfatiza todo um sistema de relações que pode 
incluir o sexo, mas não é diretamente determinado pelo sexo, nem determina diretamente a sexualidade". Ao nos referirmos ao gênero, Scott (1995) nos traz uma definição para o mesmo:

[...] O termo "gênero" torna-se uma forma de indicar "construções culturais" a criação inteiramente social de idéias sobre os papéis adequados aos homens e às mulheres. Trata-se de uma forma de se referir às origens exclusivamente sociais das identidades subjetivas de homens e de mulheres. "Gênero" é, segundo esta definição, uma categoria social imposta sobre um corpo sexuado (p. 75).

Como produção social, o gênero e suas atribuições construídas e naturalizadas são produtos das relações de poder no âmbito da cultura. Sobre este conceito, Dagmar Meyer nos apresenta que "o conceito de gênero remete a todas as formas de construção social, cultural e lingüística implicadas com processos que diferenciam mulheres de homens, incluindo aqueles processos que produzem seus corpos” (MEYER, 2004, p. $15)$.

Contribuindo com este debate, Stuart Hall (1997, p. 19) afirma que "cada movimento que fizemos é normativamente regulado no sentido de que, do início ao fim, foi guiado por um conjunto de normas e conhecimentos culturais". Assim podemos associar gênero e o conceito de cultura para problematizarmos e compreendermos como os movimentos, os gestos, os gostos, os desejos, as práticas representadas pelas crianças na Educação Infantil são influenciadas e moldadas social e culturalmente, seguindo modelos hegemônicos de gênero. Também é importante ressaltarmos que esse modelo hegemônico de gênero é produto de disputas de poder acionadas e posicionadas a partir de diferentes representações de ser masculino e de ser feminino em determinado contexto cultural.

Meyer (2004, p. 14) nos diz que,

Os modos pelos quais determinadas características femininas e masculinas são representadas como mais ou menos valorizadas, as formas pelas quais se distingue feminino de masculino, aquilo que se torna possível pensar e dizer sobre mulheres e homens que vai constituir o que é inscrito no corpo e definido e vivido como masculinidade e feminilidade, em uma dada cultura, em um determinado momento histórico.

Nesta perspectiva construcionista de gênero, a educação do feminino e do masculino na escola e na Educação Física escolar deve ser analisada, visto que são 
espaços de produção cultural, bem como acionam potentes efeitos nos corpos. O espaço escolar por sua vez é um espaço que impulsiona a nos reconhecermos como homens ou mulheres, pois a escola inscreve a todo instante sobre nossos corpos orientações de comportamentos normativos que devemos ter.

Percebemos, dessa forma, que compreender as relações de gênero e correlacionar seus atravessamentos a instituições públicas e democráticas constitui-se como um exercício de contrapor aos modos hegemônicos de normalização dos corpos, bem como de evidenciá-los no âmbito das práticas educativas. Contribuindo com este debate, Meyer (2009) conceitua educação como,

[...] o conjunto de processos através do qual os indivíduos são transformados ou se transformam em sujeitos de uma cultura. Tornar-se sujeito de uma cultura envolve um complexo de forças e de processos de aprendizagem que hoje deriva de uma infinidade de instituições e 'lugares pedagógicos' para além da família, da igreja e da escola e engloba uma ampla e variada gama de processos educativos, incluindo aqueles que são chamadas em outras teorizações de "socialização". (p. 222).

Então a educação é um fator importante na produção dos corpos, pois através dela os sujeitos são transformados por relações de poder a fim de se englobar nos aspectos da cultura almejada por aquela instituição, ou seja, transformar os sujeitos em seres hegemônicos de uma certa cultura.

Priscila Dornelles, (2007, p. 95) diz que, “é importante marcar que o corpo é, sempre, resultado provisório e inacabado. Atravessado e constituído por categorias sociais como classe, geração, raça/etnia, gênero e sexualidade pode ser significado de diversas formas”. Então, o corpo é resultado provisório e inacabado, assim as categorias sociais atravessam esse corpo moldando-os e inserindo valores, podemos entender o ambiente escolar como um fator sócio cultural que não apenas marca os corpos, mais sim que vai muito além de marcar, a escola produz corpos adestrados, ordenando assim como cada criança deve se comportar, agir e brincar segundo certas medidas generificadoras.

\section{AS RELAÇÕES DE GÊNERO NA EDUCAÇÃO INFANTIL}

Ao investigarmos as relações de gênero na escola e na educação infantil, podemos indicar que as situações apresentadas pelos/as participantes da pesquisa evidenciam que há uma construção social da escola baseada no binarismo de gênero. Podemos 
compreender que os corpos são adestrados, produzidos silenciosamente na escola por uma dada cultura a fim de torná-los homens ou mulheres com comportamentos, falas e representações homogêneas consideradas referentes nesta cultura almejada. Ao falar da instituição escola, a autora Louro (1997) nos diz que "Ali se aprende a olhar e a se olhar, se aprende a ouvir, a falar e a calar; se aprende a preferir" (LOURO, 1997, p. 61). Acreditamos que uma importante posição é assumirmos que a escola não é um ambiente neutro na formação das crianças, visto que ela institui como deve ser organizada a vida, os corpos e os referentes sociais dos/das discentes. Ensina-se a preferir ser menina ou menino neste espaço, produzem-se diversas desigualdades sociais, inclusive, as de gênero.

Segundo a Emenda Constitucional $n^{0}$ 59/2009, é de a obrigatoriedade ofertar a Educação Básica dos 4 aos 17 anos. Essa extensão da obrigatoriedade foi incluída na LDB em 2013, consagrando plenamente a obrigatoriedade de matrícula de todas as crianças de 4 e 5 anos em instituições de Educação Infantil ${ }^{5}$.

Nesta etapa, apesar de ser um primeiro período na escola, podemos observar, há sempre aquela cobrança em relação ao gênero, buscando aproximar aquela criança dos padrões culturais heteronormativos ${ }^{6}$. Ao buscarmos compreender como se dá essa organização das relações de gênero na escola e na Educação Infantil, tivemos algumas contribuições dos/as entrevistados/as para refletir acerca dos modos de educação para o gênero. Sobre isso, a professora Malú nos falou que: "as pessoas ficam reclamando o jeito que a criança é, um dia mesmo a merendeira mesmo mandou o menino falar direito: fala como homem, porque o menino falava muito fino". (Entrevistada Malú, $01 / 10 / 2016$, p. 4). Através dessa fala percebemos que a comunidade escolar busca instruir os/as alunos/as a se encaixarem em padrões de gênero. Eles/Elas têm que ter comportamentos de acordo com o que é naturalizado para o seu corpo a partir do seu sexo.

Há aquelas crianças que fogem desses padrões de gênero. Em geral, a escola tenta enquadrá-los/as reorganizando seus corpos através de vigilâncias constantes,

\footnotetext{
${ }^{5}$ Primeira etapa da educação básica, oferecida em creches e pré-escolas, às quais se caracterizam como espaços institucionais não domésticos que constituem estabelecimentos educacionais públicos ou privados que educam e cuidam de crianças de 0 a 5 anos de idade no período diurno, em jornada integral ou parcial, regulados e supervisionados por órgão competente do sistema de ensino e submetidos a controle social (MINISTÉRIO DA EDUCAÇÃO, 2010, p. 12).

${ }^{6}$ Onde apenas comportamentos e atitudes heterossexuais são considerados como únicos e corretos segundo a norma de uma dada cultura.
} 
punições, métodos de exame das causas destes desvios para que se tornem sujeitos que transitam dentro do padrão normativo. Contribuindo com essa discussão, Dornelles (2013, p. 30) diz que "as penalidades agregadas funcionam num sentido corretivo de forma a regular os sujeitos a graus mais próximos da norma, buscando, assim, constituílos como normais". Nesse sentido, concordando com a autora, entendemos que a escola aciona estas estratégias para controlar os corpos e aproximá-los da norma cultural.

A professora Tatiana contribui com essa afirmação sobre táticas de punição no ambiente escolar quando relata que:

Aconteceu de menina sentar de perna aberta e a professora dizer: “Fecha a perna que menina não fica de perna aberta! Conserta o cabelo! Amarra o cabelo!" Já pra identificar o que é comportamento de menina e o que é comportamento de menino. (Entrevistada TATIANA, $14 / 10 / 2016$, p.5).

Quando pensamos nas atividades recreativas que acontecem na escola, percebemos que o uso pedagógico e contínuo da separação de meninos e meninas é uma realidade da Educação Infantil, bem como é uma prática pedagógica que produz e naturaliza o binarismo de gênero nas aulas de Educação de Física. Sobre essa discussão, Eustáquia Salvadora de Sousa e Helena Altmann (1999) apontam que,

Ademais, meninas não são as únicas excluídas, pois os meninos mais novos e os considerados fracos ou maus jogadores frequentam banco de reserva durante aulas e recreio, e em quadra recebe a bola com menor frequência até mesmo do que algumas meninas. (SOUSA e ALTMANN, 1999, p. 52).

A análise das entrevistas nos permite apontar que há uma separação de meninos e meninas referente também às cores, ao uso dos objetos e à experimentação das brincadeiras, como nos diz a professora Malú (2016, p.3) "na atividade de pintura e massinha de modelar, os meninos não queriam a cor rosa porque era de mulher". As atividades também eram classificadas como apenas de meninos e apenas de meninas.

Meninos que participassem da atividade "de menina" eram hostilizados pelos/as colegas e, em geral, eram chamados de "viado" ou "menininha". Sobre isso, a professora Tatiana (2016, p. 4) exemplifica que "aqueles alunos que ficam mais quietos eles ficam perturbando, o menino que fica mais quieto e retraído na sala eles disseram que o menino era viadinho". Segundo as falas dos/as entrevistados/as, esses xingamentos sempre ocorriam de maneira mais acentuada em relação aos meninos. Considerando a produção sobre gênero na Educação, entendemos que o xingar se 
constitui como uma prática coercitiva para que estes meninos não se afastem da heterossexualidade, se distanciando de qualquer comportamento feminino ou homossexual.

Ainda sobre o funcionamento do gênero binário como referência das práticas na Educação Infantil, as falas dos/as entrevistados/as são unânimes em afirmar que quando existem atividades de pintar, por exemplo, as meninas optam geralmente pela cor rosa e os meninos pela cor azul. A professora Malú explica que:

[...] muitas vezes, as crianças já ficavam com essa besteira de dizer que só quer brinquedo rosa, ou então que não querer o objeto porque é rosa, e a cor rosa é de menina, os meninos falavam que se brincar virava "viado"”. (Entrevistada Malú, 01/10/2016, p.1).

Sobre isso, Alexandre Bello (2006, p.70) contribui dizendo que "o brincar e o brinquedo, são, portanto, nesse contexto, um instrumento de poder que é acionado constantemente para definir/produzir determinadas formas de gênero". Podemos compreender assim, que na Educação Infantil os brinquedos são utilizados como técnicas de (re) afirmação de gênero, fazendo com que desde a infância as crianças comessem a utilizar esses brinquedos para que eles reforcem as expressões de gênero normatizadas pela escola. Assim, controla-se a forma de brincar de meninos e meninas, distanciando-os/as de brincadeiras e brinquedos considerados próprios "do outro gênero" e, supostamente, com isso, afastando-os/as da homossexualidade/lesbianidade, ou seja, do indesejável. Ainda segundo o referido autor, determinados brinquedos ou brincadeiras têm o intuito de produzir a criança para a heterossexualidade e assim poder controlar tanto o brincar, quanto induzir a formação da sua identidade de gênero.

Mesmo a escola produzindo para os padrões heteronormativos, existem sujeitos que escapam das normas. No exemplo do menino que fala sobre a camisa do pai que era da cor rosa indica o movimento de liberdade, do também poder usar roupa da cor rosa, e a professora organizou uma votação para ver a cor que ganharia e assim nos exemplifica a democracia que deveria ser base das práticas escolares.

Ao analisarmos as falas dos/as entrevistados/as ficou evidente também que há unanimidade em relação a um esforço por parte destes docentes na organização dos/as alunos/as nas atividades para garantir uma aula mista com cooperação e interação de todas as crianças. Sobre isso, a professora Carmem relata como realizava a organização da turma: 
A gente sempre buscou trabalhar em grupo misto, tanto menina quanto menino, na verdade a gente mesmo que organizava os grupos (Entrevistada Carmem, 09/10/2016, p.1).

A professora Malú também deixa explícito esse esforço para que houvesse cooperação de meninos e meninas nas aulas:

Eu sempre procurava fazer atividade que envolvesse as duas partes, quando tinha alguma atividade em grupo eu colocava meninos e meninas no grupo pra não haver separação (Entrevistada Malú, 01/10/2016, p.2).

Outro ponto importante a ser destacado, é sobre o papel da família nas falas dos/as entrevistados/as. Alguns/as alegam/alegaram que a família era a responsável principal por influenciar nos gostos e nos comportamentos das crianças segundo o gênero, como nos disse o professor estagiário Igor: "Isso aí é o pai e a mãe que acabam influenciando que determinadas cores são para um gênero e não para o outro". (Entrevistado Igor, 14/10/2016, p.4).

Apesar de considerarmos que a família é uma instituição social que realiza potentes investimentos e educabilidades para o gênero, a fala de Igor quer posicionar a escola como isenta e/ou neutra na formação da identidade de gênero dos/das alunos/as argumento que questionamos. Para Igor, alunos/as aprendem referências de gênero e de sexualidade com os responsáveis no seio da família. Ou seja, fora da escola. O perigo deste tipo de argumento é quando assumimos que na escola há igualdade plena e/ou indicações que temos aí uma instituição ausente de relações de poder.

\section{A EDUCAÇÃO FÍSICA NA EDUCAÇÃO INFANTIL}

A educação física na educação infantil pode configurar-se como um espaço em que a criança brinque através de movimentos corporais, utilizando seu corpo como principal instrumento, construindo assim uma linguagem corporal ampla. Podemos compreender a importância da brincadeira na Educação Infantil como método de aprendizagem e fixação de conhecimentos, pois, através do brincar as crianças fazem relações com o cotidiano da cultura na qual está inserida e assim conseguem fazer assimilação da realidade de uma forma prazerosa. Desse mesmo modo são transmitidas às crianças informações a respeito de como meninas e meninos devem se vestir, se comportar, quais brinquedos devem utilizar, quais cores devem usar entre outras, buscando assim identificar, distinguir e reforçar o seu gênero, para que elas possam se 
comparar com o/a outro/a colega do gênero oposto e saber quais as diferenças existentes entre ambos.

Para Eliana Ayoub (2001),

Criança é quase sinônimo de movimento; movimentando-se ela se descobre, descobre o outro, descobre o mundo à sua volta e suas múltiplas linguagens. Criança é quase sinônimo de brincar; brincando ela se descobre, descobre o outro, descobre o mundo à sua volta e suas múltiplas linguagens. (AYOUB, 2001, p. 57).

Podemos entender que a criança consegue assimilar as coisas através das brincadeiras, porém nós professores/as de Educação Física devemos favorecer essas brincadeiras de forma sistematizada para que a Educação não seja vista apenas como um momento de lazer e, que vai, além disso, havendo sempre uma mediação de um professor no processo educativo com a criança.

A partir das falas das entrevistadas podemos perceber que alguns/as professores/as detém também de muitas formas para promover a interação e a cooperação - fundamentais para o trabalho coletivo - entre os/as alunos/as através de diversas práticas pedagógicas nas aulas de Educação Física na Educação Infantil.

A fala da professora Ana nos mostra uma situação que ocorreu com a sua turma e como ela reagiu no momento,

As meninas vem reclamar dizendo que os meninos não deixaram jogar, aí a gente sempre consegue outro jeito, consegue outra bola, a gente fica até meio assim né, que eles acham que é só de menino, e as vezes nesse momento a gente nem para pra conversar né, por que nesse momento era pra gente falar assim: não, futebol é de menina também, as vezes a gente passa abatido, aí a gente fala: vai brincar de outra coisa, para não ter problema. (Entrevistada Ana, 08/10/2016, p. 3).

A professora Ana nos mostrou nessa fala a situação de um jogo onde os meninos não permitiram a participação das meninas e ela obteve de outras maneiras para evitar conflitos de gênero nas aulas, que, nesse caso, foi conseguindo outra bola e outra atividade para as meninas. Agindo dessa forma, a professora acabou por continuar realizando uma segregação das práticas corporais de meninos e meninas educando assim para o gênero almejado pela sociedade, onde os meninos podem exercer apenas uma forma de masculinidade e as meninas apenas uma forma de feminilidade - aquela em que a menina não poderia jogar futebol, pois estaria se afastando dos padrões da norma. 
A professora estagiária Beatriz, diferentemente da professora Ana, relatou que:

[...] tinha que controlar, tinha que sentar e conversar, mas mesmo assim com o passar do tempo da atividade eles iam acostumando e até essa resistência ia diminuindo; tinha atividades de revezamento que a gente mandava menino e menina pegar na mão pra fazer a atividade e eles faziam numa boa. (Entrevistada Beatriz, 14/10/2016, p.3-4).

A partir das falas da professora Ana e da professora estagiária Beatriz, podemos analisar que há divergências em relação aos modos do/a professor/a reagir pedagogicamente aos conflitos de gêneros existentes no decorrer das aulas mistas. Como verifica-se nas falas citadas anteriormente, a primeira deixou prevalecer a vontade dos meninos, e as meninas foram excluídas tendo que planejar e produzir outra atividade para elas, ou seja, separando por gênero. A segunda fala evidencia a possibilidade de trato pedagógico utilizando o recurso do diálogo para quando existiam esses conflitos e, assim, romper com essa resistência. Proposta que gerava participação de todos/as.

Assim, percebemos que as práticas pedagógicas realizadas pela Educação Física na Educação Infantil no currículo escolar não são neutras, pois buscam educar para o gênero, ensinando o que meninos podem fazer e vice e versa. Professores/as entrevistados/as nesta pesquisa utilizam de práticas pedagógicas para romper com essa educabilidade dos corpos ou apenas seguir esse modelo hegemônico contido na escola. Daí é fundamental argumentar que o compromisso docente na escola deve ser o de respeitar e promover atividades sem distinção de acesso e/ou segregação entre meninos e meninas.

$\mathrm{Na}$ Educação Física escolar as práticas de educabilidade dos corpos são apresentadas por modos de se movimentarem nas aulas, de expressarem seus sentimentos, suas expressões faciais e seus comportamentos, quando, por exemplo, um/a professor/a entrega a bola para os meninos e a corda para as meninas já está reafirmando seus lugares nas aulas de Educação Física e consequentemente, na sociedade demonstrando o lugar da menina e do menino em diferentes instâncias. Contribuindo com essa discussão Silvana Goellner (2010, p. 74) nos afirma que "[...] o corpo é educado por meio de um processo contínuo, cuja ação vem conformando formas de ser, de parecer e de se comportar". Assim reconhecemos que os corpos na Educação Infantil passam por um processo de educabilidade buscando classificá-los e aproximá-los dos padrões exigidos na norma. 
Para Cláudia Vianna e Daniela Finco (2009, p. 270)

Ultrapassar a desigualdade de gênero pressupõe, assim, compreender o caráter social de sua produção, a maneira como nossa sociedade opõe, hierarquiza e naturaliza as diferenças entre os sexos, reduzindo-as às características físicas tidas como naturais e, consequentemente, imutáveis.

E na Educação Física situações de superioridade masculina acontece muito, pois fica explícito o modo que a sexualidade é apresentada durante as práticas corporais de maneira instintiva como se fosse algo "natural" dos meninos ficarem à frente das meninas, agredi-las, pegá-las em partes íntimas e xingá-las nas aulas de Educação Física. Como ocorreu mesmo na fala da professora Eva:

Depois que eu vi a cena dos meninos pegando ela que eu não gostei, ela tava com um ar de pedindo socorro, que alguém acudisse ela, nesse dia eu reclamei os meninos e depois chamei ela separado e disse se ela tivesse sentido que estava sendo prejudicada, se os meninos pegaram em partes coisa assim entendeu, que ela fale e que ela não deixe entendeu, porque eu acho que a gente como adulto tem que proteger a criança né, e aí disse pra ela não brincar mais com os meninos. (Entrevistada Eva, 18/10/2016, p.5).

Ela nos relata que percebeu que a menina estava sendo agredida pelos meninos aí acabou com a brincadeira e chamou a atenção da menina para não brincar com meninos porque os meninos têm brincadeiras agressivas. A prática pedagógica desta professora é questionável, pois ela chamou apenas a atenção da menina, deixando os meninos isentos de qualquer culpa. Esta ação, aparentemente, naturaliza o lugar de um feminino violado e, ao mesmo tempo, responsável pela sua agressão. E/Ou como se fosse do instinto masculino ser agressor e, por isso, não educável, não investido para uma conversa, uma sanção pela escola. Muitas vezes, ocorre a separação de maneira proposital a fim de evitar conflitos de gênero como o relatado acima durante as aulas.

Então percebemos que a separação acontece de maneira tão acentuada que há divisão entre espaços e conteúdos nas aulas de Educação Física onde em algumas atividades, como por exemplo, pular corda, cantiga de roda não fossem praticadas pelos meninos por ser considerada como atividade do sexo oposto, e jogar futebol, brincar de 
correr, de carrinho fossem atividades que apenas meninos participassem como se essas atividades citadas acima fossem somente para os meninos.

\section{CONSIDERAÇÕES FINAIS}

Primeiramente foi possível averiguarmos nessa pesquisa que a separação de gênero é muito forte na Educação Infantil, pois a partir das entrevistas ficou notório a separação de espaços, cores, materiais, brinquedos e de atividades. Desde cores de armários diferenciadas à fileiras separadas segundo o gênero.

Então percebemos a partir desses relatos que as crianças na educação infantil se separam a todo instante segundo o gênero, sempre meninas de um lado e menino de outro, mas quero salientar também que essa separação não é algo natural, mais sim como uma produção cultural dos corpos, como nos diz Dornelles (2013, p. 115) "A produção dos corpos na escola e na Educação Física escolar é constante, seja através dos silêncios cotidianos da negação do seu trato conceitual e/ou da naturalização da heterossexualidade", assim percebemos que no decorrer das atividades só queriam ficar meninas com meninas e meninos com meninos deixando explicito sua sexualidade e sua identidade de gênero naturalizada e se acaso algum/a por vontade própria fosse fazer a atividade com um/a aluno/a do sexo oposto era hostilizado e discriminado com palavras pejorativas por parte dos/as próprios colegas.

Contribuindo com essa discussão SOUSA e ALTMANN (1999, p. 62) diz que,

$\mathrm{Na}$ escola, estudantes estão constantemente vigiando as habilidades, as atitudes, o gênero e a sexualidade dos colegas. Quando, por exemplo, meninos e meninas são vistos juntos, é comum ocorrerem comentários pejorativos ou "gozações" entre outros colegas, como chamando-os de namorados ou questionando sua sexualidade por a atividade ser considerada feminina ou masculina.

Através dessas falas percebemos a fundamental importância do papel do/a professor/a para quebrar essas questões de gênero na escola, pois ficou perceptível que há um investimento docente para que meninos e meninas realizem as atividades juntos, porque ao deixar eles/as se auto organizando durante as aulas a separação ficava evidente. 
Desde o que foi exposto até então, defendemos que a Educação Física escolar na Educação Infantil é repleta de padrões heteronormativos que expõem quais devem ser os comportamentos de meninas e de meninos, sempre deixando evidente a separação dos mesmos, usando da técnica de vigilância e da punição para controlar os corpos e seus modos de agir e punindo aquele que fogem da norma. E nas aulas de Educação Física ou recreação fica ainda mais evidente essa organização das aulas na Educação Infantil onde os/as alunos/as já se separam sozinhos quando se organizam e isso é tido como "normal” o que na verdade não é, mas, é apenas uma busca para normatizar os corpos como heterossexual em uma dada cultura.

Em seguida constatamos a ausência das aulas específicas de Educação Física na Educação Infantil no referido Distrito, que é uma zona rural do município de Amargosa, pois existe o dia do movimento ou a recreação, porém queremos salientar que recreação e dia do movimento não é Educação Física, que é esse momento citado pelos/as professores/as onde as crianças brincam livremente ou quando os/as professores/as organizam as atividades. Consideramos importante ressaltar que essa recreação acontecia de maneira separada na maioria das vezes, tanto os alunos sozinhos que já se separam havendo intervenção ou não do/a professora para romper com essa separação ou até mesmo os/as professores/as já organizam separadamente segundo o gênero para evitar conflitos, porém não apenas na hora da recreação, mais sim em diversos momentos no ambiente escolar.

E logo após nós trazemos o argumento de que a auto-organização dos/as alunos/as que acontecem de maneira separada é tida como "natural" e muitas vezes por conta disso não é questionada, mais como disse alguns/as entrevistados e concordando com alguns/as dele/as a escola reforça e cria modelos homogêneos de ser homem e mulher. Assim o papel docente implica no incentivo das aulas de Educação Física sem separação de gênero, onde os/as alunos/as possam se auto descobrir no contato um com o outro e ter a liberdade de expressar e viver sua masculinidade ou feminilidade da maneira que sentirem vontade.

Portanto, concluímos que as aulas de Educação Física na Educação Infantil são organizadas separadamente segundo o gênero, seja por espaços, cores, atividades, comportamentos e modos de falar, e essas separações são muitas vezes vista como natural, e a instituição escolar por sua vez vem atuando na fabricação dos corpos naturalizados, pois há uma construção cultural que determina através de relações de 
poder o que deve ser compreendido como de menina e como de menino, porém destacamos aí o importante papel do/a professor/a como mediador do conhecimento no ambiente escolar, desnaturalizando conceitos relacionados ao gênero, mas, muitas vezes essas situações que emergem na Educação Física escolar na Educação Infantil passam despercebidas pelo olhar docente. Assim, essa pesquisa contribuiu para aprimorar nossos conhecimentos como professoras de Educação Física e aperfeiçoar os conhecimentos sobre relações de gênero e as relações de poder que atravessam os corpos no ambiente escolar e principalmente em aulas de Educação Física na Educação Infantil.

\section{REFERÊNCIAS}

AYOUB, Eliana. Reflexões sobre a educação física na educação infantil. Revista Paulista Educação Física. São Paulo, v. 4, p.53-60, 2001.

BELLO, Alexandre. T. Sujeitos infantis masculinos: homens por vir? 2006. $117 \mathrm{f}$. Dissertação (Mestrado em Educação). Faculdade de Educação, Universidade Federal do Rio Grande do Sul. Porto Alegre, 2006.

BLOG DE CORTA-MÃO. Disponível em: $<\mathrm{http}$ :/cortamaoamargosa.blogspot.com.br/p/dados-geograficos.html $>$. Acesso em: 26 mai. 2017.

BRASIL. Diretrizes Curriculares Nacionais Gerais da Educação Básica, Ministério da Educação. Secretaria de Educação Básica. Diretoria de Currículos e Educação Integral. Brasília: MEC, SEB, DICEI, 2013.

BRASIL. Ministério da Educação. Secretaria de Educação Básica. Diretrizes curriculares nacionais para a educação infantil: MEC, SEB, 2010.

DORNELLES, Priscila. G. A (Hetero) normalização dos corpos em práticas pedagógicas da Educação Física escolar. 2013. 193f. Tese (Doutorado em Educação). Faculdade de Educação da Universidade Federal do Rio Grande do Sul. Porto Alegre, 2013.

DORNELLES, Priscila. G. Destinos distintos? A separação entre meninos e meninas na Educação Física escolar na perspectiva de gênero. 156f. Dissertação (Mestrado em Educação). Faculdade de Educação da Universidade Federal do Rio Grande do Sul, Porto Alegre, 2007.

GIL, Antônio. C. Métodos e técnicas de pesquisa social. 6. ed. - São Paulo: Atlas, 2014. GOELLNER, Silvana. V. A educação dos corpos, dos gêneros e das sexualidades e o reconhecimento da diversidade. Cadernos de formação RBCE, v. 1, $\mathrm{n}^{\mathbf{0}}$ 2, p. 71-83, 2010 . 
HALL, Stuart. A centralidade da cultura: notas sobre as revoluções culturais do nosso tempo. Educação \& Realidade; org: Kenneth Thompson; v. 22, nº 2, p. 15-46, jul./dez. Inglaterra, 1997.

LOURO, Guacira. L. Gênero, sexualidade e educação: Uma perspectiva pósestruturalista. Petrópolis, Rio de Janeiro; Ed. Vozes, 1997.

MEYER, Dagmar. E. E. Teorias e políticas de gênero: fragmentos históricos e desafios atuais. Revista Bras. Enferm., Brasília, DF; jan/fev; n. 1, vol. 57, p.13-18, 2004.

MEYER, Dagmar. E. E. Corpo, Violência e Educação: uma abordagem de gênero. In: JUNQUEIRA, Rogério Diniz; (org). Diversidade Sexual na Educação: problematizações sobre a homofobia nas escolas. Brasília: Ministério da Educação, Secretaria de Educação Continuada, Alfabetização e Diversidade, UNESCO, 2009.

SCOTT, Joan. Gênero: uma categoria útil de análise histórica. Tradução: Guacira Lopes Louro. Educação e realidade. v.20, n.2, jul./dez, 1995.

SOUSA, Eustáquia. S; ALTMANN, Helena. Meninos e meninas: Expectativas corporais e implicações na educação física escolar. Cadernos Cedes, ano XIX, nº 48, vol.19, p. 52-68, Agosto de 1999.

VIANNA, Cláudia; FINCO, Daniela. Meninas e meninos na Educação Infantil: uma questão de gênero e poder. Cadernos pagu, n. 33, p. 265-283, julho-dezembro de 2009. 
